\title{
RESENHA
}

\section{CONSTRUÇÃO DE IDENTIDADES: DISCENTE E DOCENTES}

DOI: http://dx.doi.org/10.1590/2236-3459/63902

\section{IDENTITIES OF CONSTRUCTION: STUDENTS AND TEACHERS}

\author{
Maria Helena Camara Bastos \\ Pontifícia Universidade Católica do Rio Grande do Sul, Brasil.
}

$\cos 8$

ASCENZI, Anna; SANI, Roberto. Tra disciplinamento sociale ed educazione alla cittadinanza: l'insegnamento dei Diritti e Doveri nelle scuole dell'Italia unita (1861-1900). Macerta: Università di Macerata, 2016.

ASCENZI, Anna; SANI, Roberto. Oscuri martiri, eroi del dovere: memoria e celebrazione del maestro elementare attraverso i necrologi pubblicati sulle riviste didattiche e magistral nel primo secolo dell'Italia unita (1861-1961). Milano: Franco Angeli, $2016 .{ }^{1}$

nna Ascenzi e Roberto Sani integram o Centro di documentazione e ricerca
sulla storia del libro scolastico e della letteratura per l'infanzia - Cesco (2004),
vinculado ao Dipartimento di Scienze della formazione, dei beni culturali e del turismo da Università degli studi di Macerata/ltália. A professora Ascenzi coordena o Cesco e o Museo della Scuola Paolo e Ornella Ricca (2010). O professor Sani é o editor da revista History of Education \& Children's Literature (2006).

\footnotetext{
${ }^{1}$ Livros italianos podem ser adquiridos pelos sites libreriauniversitaria; ibs.it; amazon.it Hist. Educ. (Online) 
A primeira obra - Tra disciplinamento sociale ed educazione alla cittadinanza: l'insegnamento dei Diritti e Doveri nelle scuole dell'Italia unita (1861-1900) - integra a coleção Biblioteca di History of Education \& Children's Literature, dirigida pelos referidos professores desde 2011, correspondendo ao volume 15. O texto é composto por uma introdução e cinco capítulos, seguidos de três apêndices e índice de nomes.

$\mathrm{Na}$ introdução os autores apresentam o objetivo da pesquisa²: o aprofundamento e a análise das características da disciplina Direitos e Deveres do Cidadão, incluída como obrigatória na escola elementar e nos cursos de educação secundária italianos - escola normal e escola técnica - depois da Unificação (1861), com a finalidade de promover, na nova geração, os valores da cidadania e o sentimento de pertencimento a um novo país unificado.

O período abarcado é de 1861 a 1900. Com uma reconstrução histórica do contexto político e ideológico da estrutura oligárquica do país e com apoio em uma multiplicidade de fontes documentais - legislação, programas, conteúdos, horário, manuais, relatórios de inspetores e professores, características do corpo docente, avaliação, métodos - os autores explicitam a função a ser exercida pela disciplina Direitos e Deveres do Cidadão na escola italiana:

Destacar a profunda diferença entre a cidadania ideal, aquela delineada sobre bases de um refinamento do que é direito e deveres em abstrato, e a cidadania real, expressão da ideia geral de sociedade - e de Estado - que a classe dominante tentava realizar. Objetivava, substancialmente, ser um dispositivo de formação do cidadão consciente de seus direitos e deveres e de assumir suas responsabilidades civis, com um ensinamento voltado a garantir um sistema de regulação e legitimação, sob uma base ética e jurídica, de um ordenamento rigidamente classista da sociedade e o sistema de valores propugnados pelas elites burguesas. (2016a, p. 11)

Para demonstrar o objetivo da inserção da disciplina Direitos e Deveres do Cidadão Ascenzi e Sani analisam, no capítulo 1 - Tra pedagogia e política: i Diritti e doveri del cittadino nell'ordinamento scolastico casatiano -, a legislação da instrução pública de 1859, Lei Casati, sobre o ensino da disciplina introduzida na escola elementar, na escola técnica e normal e nas classes inferiores ${ }^{3}$. Chamam a atenção que essa disciplina não era ministrada na escola secunária frequentada pelos filhos da elite e da pequena burguesia. Essa exclusão deixa evidente que se destinava às classes mais baixas da população, "fornecendo uma instrução política, capaz de inspirar sentimentos de honestidade, de amor à família, a si próprio, ao trabalho, à pátria, e, em consequência, às leis" (2016a, p. 17). Em síntese, com função de controle ideológico e de disciplinamento das classes populares, tinha em vista "formar um bom cidadão, que trabalha pelo progresso e a propsperidade da sociedade e da nação" (2016a, p. 17).

\footnotetext{
${ }^{2}$ Esta é parte de uma pesquisa maior que terá continuidade com a publicação posterior de um volume sobre o período das reformas Genttile (1923) e os anos 1920e fascistas.

${ }^{3} \mathrm{Na}$ Lei Casati (1859), a escola elementar compreendia quatro classes: a primeira e segunda eram as classes inferiores, a terceira e quarta classes superiores. A instrução técnica foi dividida em dois graus: o grau inferior se chamava escola técnica e abrangia três anos; o grau superior se chamava Instituto Técnico e abrangia de dois ou três anos, dependendo do tipo de seção. A Escola Normal com três anos era dividida em duas etapas: inferior, os dois primeiros anos, e superior, que correspondia ao terceiro ano. 
No segundo capítulo, intitulado Formare il 'galantuomo operoso: l'insegnamento dei Diritti e doveri del cittadino nelle scuola elementari, os autores analisam as alterações e prescrições da legislação e regulamentos sobre o programa da disciplina durante as quatro décadas, de 1860 a 1900, a ser ministrada no terceiro, quarto e quinto ano da escola elementar. Os programas, em uma síntese ampla, abarcavam como principais tópicos: as primeiras noções de deveres do homem e do cidadão, os direitos e os deveres do homem com a família, a sociedade, a pátria.

No apêndice 1 o leitor pode verificar as instruções emanadas dos programas da disciplina para as escolas elementares. Por exemplo: o de 1894 estabelece, para as disciplinas História da Itália, Geografia e Direitos e Deveres do Cidadão, para a terceira classe do curso inferior, temas sobre direitos e deveres do cidadão; para a quarta classe do curso superior temas relativos à família, sociedade, nação e ao governo; para a quinta classe do curso superior, direitos e deveres do cidadão a partir do Estatuto, temas sobre o ordenamento político e administrativo do Reino (2016a). A análise da historicidade dos programas da disciplina permite depreender as finalidades propugnadas pelas autoridades governamentais e elite dirigente: "a escola elementar deve se constituir em um instrumento de verdadeira educação nacional do nosso povo, destinada a disseminar nas gerações futuras o elemento de um rápido progresso civil” (2016a, p. 38).

No terceiro capítulo - Per preparare al loro alto ufficio i generosi educatori de'figlioli del popolo: l'insegnamento dei Diritti e doveri del citadino nelle scuole normali e magistrali - , os autores analisam a inclusão da disciplina Direitos e Deveres nos cursos de formação de professores, juntamente com a de Religião e Moral. A inclusão dessas disciplinas visava a imbuir o futuro professor da escola elementar de um "verdadeiro sentimento patriótico, principal e indispensável fundamento da educação política” (2016a, p. 54). Além da análise dos programas os pesquisadores também abordam os manuais indicados à formação dos professores.

No quarto capítulo - Per fornire una necessaria e compiuta istruzione civile e politica alla piccola borghesia urbana e ai nuovi ceti produtivi: l'insegnamento dei Diritti e doveri del cittadino nelle scuole tecniche -, Ascenzi e Sani (2016a) mostram como a formação deveria objetivar um crescimento pessoal e profissional, com a elevação civil e política da juventude da classe trabalhadora e da pequena burguesia urbana. Assim como os futuros professores, os novos trabalhadores também deveriam estar imbuídos da importância de sua participação e contribuição à edificação do novo Estado por uma educação ético-civil, de exaltação da pátria e de institucionalização do estado liberal.

No último capítulo - Retoriche della cittadinanza e struttura classista dell'ltalia liberale dell' ottocento: lo scarto tra riconoscimento formale dei diritti e condizioni reali per il loro effettivo esercizio - são analisados, a partir do Estatuto do Reino da Itália - Statuto Albertino (1848) -, os artigos relativos aos Direitos e Deveres do Cidadão (art. 24-32), os quais permitem verificar nos programas e manuais escolares que são somente "valores formais, teóricos, abstratos", pois a grande maioria do povo não tinha acesso aos direitos políticos, de associação, de expressão. Por exemplo: o direito de voto era permitido somente aos homens com idade superior a 25 anos, alfabetizados, que pagassem um imposto maior que 40 liras italianas. Concluem que o ensino da disciplina visava a que o estudante adquirisse um "sistema de regulação, que legitimasse, somente no campo ético 
e jurídico, o ordenamento rigidamente classista da sociedade e o sistema de valores preconizado pela elite burguesa, [...] promovendo uma verdadeira universalização dos princípios e modelos burgueses" (2016a, p. 90).

A obra é constituída de três apêndices (p. 91-163): Programas didáticos da disciplina para a escola elementar (1860-1894); Programas didáticos da disciplina para a escola técnica e normal (1860-1895); Repertório bibliográfico de manuais da disciplina para a escola elementar, técnica e normal (1861-1900), por ano de publicação, com quase três centenas de referências. Os autores reconhecem que esse levantamento é provisório, mas que a intenção foi dispor de um instrumento inicial de pesquisa que se constitui em um ponto de partida e de aprofundamento para pesquisas futuras.

Chamo a atenção para a preocupação dos pesquisadores com o levantamento de fontes, constituição de repertórios e disponibilização para a comunidade científica. Acredito que essa atitude precisa ser incorporada no campo da história da educação no Brasil.

Outro ponto a destacar é a necessidade de ampliar o olhar de como a formação do cidadão se processou no Brasil, ontem e hoje, em diferentes disciplinas do currículo, nos diversos níveis de ensino. Reconheço que já temos algumas pesquisas para o ensino de Educação Moral e Cívica no período das ditaduras de Getúlio Vargas (1937-1945) e no Regime Militar (1964-1985). Mas é preciso olhar para o século 19, os programas e manuais de economia política, educação moral e ensino religioso na escola elementar e secundária. Para o século 20 a disciplina Organização Social e Política Brasileira - OSPB -, os programas e os manuais não têm merecido um olhar aprofundado dos pesquisadores da área.

A segunda obra - Oscuri martiri, eroi del dovere: memoria e celebrazione del maestro elementare attraverso i necrologi pubblicati sulle riviste didattiche e magistral nel primo secolo dell'Italia unita (1861-1961) - integra a Coleção de Storia delle istituzioni educative e della Letteratura per I'Infanzia/Saggi, da editora Franco Angeli, Milano, dirigida pelas professoras Anna Ascenzi e Dorena Caroli, ambas da Università di Macerata. A pesquisa documental foi possível a partir do acervo depositado no Cesco, decorrente da publicação do Dizionario Biografico dell'Educazione 1800-200, sob a direção de G. Chiosso e R. Sani (2013).

Ao ler a presente obra lembrei-me da recente palestra que proferi na Universidade de Caxias do Sul (2015), em que chamei a atenção para o potencial que os necrológicos e obituários, publicados na imprensa periódica ou especializada, possibilitam à pesquisa historiográfica e, especialmente, para a história da educação, pois permitem rastrear os esquecidos ou anônimos professores e outros sujeitos vinculados às atividades educacionais e escolares em diferentes períodos históricos. A leitura e a análise dessa fonte permite caracterizar o sujeito da enunciação, sua auto-representação, o destinatário e a representação produzida da realidade social. $O$ discurso expresso possibilita perceber o que foi valorizado para compor o retrato do falecido, o que constituía a imagem ideal e idealizada desse ser docente.

Afinal, o que é um necrológico ou obituário? "É um texto jornalístico que faz elogios de uma personalidade (ou não) que deixa a vida para entrar na história [...]. É um reconhecimento a um legado no momento em que as pessoas próximas precisam do reconforto" (Prikladnicki, 2015, p. 3). A maioria dos jornais diários tem essa seção, 
geralmente coletada e escrita por jovens jornalistas que solicitam que o autor resuma "com lucidez, precisão e objetividade feitos de uma vida, em um tempo geralmente exíguo" (Prikladnicki, 2015, p. 3). Muitos periódicos preparam antecipadamente os obituários de personalidades, conforme relata Gay Talese, no livro Sr. Má notícia (1973).

Ascenzi e Sani (2016b) consideram um gênero literário em desuso ou marginal, mas com potencial para a pesquisa historiográfica para além de uma fonte biográfica. Destacam que é um dispositivo de

construção identitária de um grupo e da instituição que o produz, permitindo acompanhar a evolução do modelo de professor e funcionário escolar, em diferentes fases históricas e a luz de diferentes contextos ideológicos, políticos e culturais, aprofundando, por outro lado, o significado atribuído à instrução popular e à luta contra o analfabetismo. ( $p$. 8)

Com introdução e seis capítulos os autores acompanham cem anos de necrológicos publicados em revistas de educação e ensino italianas (1861-1961). A particularidade é sua publicação em revistas especializadas na área, como um reconhecimento pos-morten de sujeitos que dedicaram parte de suas vidas à atividade docente ou como funcionários em instituições escolares. Privilegiam os "protagonistas da instrução pública", isto é, os "modestos e laboriosos educadores", "os humildes e silenciosos operários da escola e do alfabeto" (Ascenzi; Sani, 2016b, p. 11).

O corpus documental é constituído de seis revistas: L'Istitutore: Foglio ebdomadario d'istruzione (1852-1894), que consideram "o primeiro e verdadeiro periódico docente e didático de âmbito nacional e de divulgação da pedagogia de matriz espiritualista e católico-liberal" (p. 13); L'Osservatore Scolastico: Giornale d'istruzione e d'educazione (1865-1899); L'Unione dei maestri elementar d'Italia (1870-1920); La Scuola Nazionale: Rassegna di educazione e istruzione per le scuole elementari e normali e per gli educatori d'infanzia (1889-1901); I Diritti della Scuola (1899-1994); Scuola Italiana Moderna (desde 1893 até hoje).

O primeiro capítulo analisa L'Istitutore e a promoção de um novo ideal de professor no início do processo da unificação nacional (1861). Os necrológicos destacavam como qualidades "o profundo sentimento pela pátria, autêntica consciência religiosa e vigorosa direção moral" (2016 b, p. 15) No segundo capítulo analisam os periódicos L'Osservatore Scolastico e La Scuola Nazionale e a responsabilidade ético-civil e patriótica dos docentes no final do oitocentos na Itália. Os necrológicos procuram construir uma memória dos professores como benfeitores do povo, apóstolos da pátria, ao mesmo tempo em que destacam a importância da preparação didática e pedagógica do professor e seu papel na luta contra o analfabetismo e pela difusão da instrução. Também são um espaço para denunciar as restrições econômicas e jurídicas relativas à carreira do magistério.

A seguir, no terceiro capítulo, os autores analisam L'Unione dei maestri elementari, no período de transição do século 19 para o século 20 . O periódico é porta-voz da batalha pela elevação da classe do magistério e pela difusão da instrução popular, isto é, a defesa dos direitos dos professores. Os necrológicos vão destacá-los como "humildes operários do pensar, que suam e se esgotam em prol dos filhos dessa Nação” (2016b, p. 35). 
O quarto capítulo analisa o periódico Scuola Italiana Moderna, o mais longevo do corpus documental, como expressão da posição católica intransigente do período de 1893 até a reforma Gentile de 1923. Defende a liberdade do ensino em respeito ao direito educativo da família, o ensino religioso na escola elementar e é contra a laicização do ensino elementar. Nessa perspectiva os necrológicos usam metáforas religiosas para a exaltação do professor "apóstolo, missionário, vocação, sacrifício, humildade, elevação espiritual, caridade cristã" (2016b, p. 47).

O quinto capítulo analisa os necrológicos das décadas de 1920 e 1930, período fascista, pelos periódicos I Diritti della Scuola e Scuola Italiana Moderna, observando o "processo de fascistização da classe do magistério e da escola popular" (2016b, p. 57). Os autores destacam que permanece uma exaltação do magistério na tradição da Igreja e do catolicismo, como um sacerdote, que atua com dignidade e consciência, mas também, contraditoriamente, respeita o sistema de valores do regime de Mussolini.

O último capítulo aborda os necrológicos na revista Scuola Italiana Moderna no período depois da segunda grande guerra. Uma primeira característica é de fazer referência àqueles professores que participaram da resistência ao regime e da guerra de libertação. Outra perspectiva é de exaltar o professor distante de qualquer clichê da propaganda nazista.

Ascenzi e Sani (2016b), nas conclusões finais da análise da representação do magistério e de funcionários escolares nos necrológicos, publicados em revistas de educação e ensino da Itália, em longa duração, destacam a importância dessa fonte para a "definição da identidade docente e para a construção e circulação de um determinado imaginário em torno da figura do professor da escola elementar" (p. 87). A idealização de atitudes, comportamentos, valores morais e éticos também expressam um paradoxo, pois ocultam a situação de marginalidade social e de um fazer pedagógico permeado de dificuldades devido à parca remuneração e condições profissionais.

As obras dos pesquisadores aqui analisadas são um contributo para ampliar a análise de temas e objetos de pesquisa com uma perspectiva internacionalizada e de educação comparada. Com a institucionalização da escola pública no século 19 observamos a ressonância de inúmeras propostas para a educação escolar, mas que necessitam ser melhor analisadas e explicitadas em diferentes suportes teóricos e metodológicos, mas também de tempo e espaço.

\section{Referências}

ASCENZI, Anna; SANI, Roberto. Tra disciplinamento sociale ed educazione alla cittadinanza: l'insegnamento dei Diritti e Doveri nelle scuole dell'Italia unita (1861-1900). Macerta: Università di Macerata, 2016.

ASCENZI, Anna; SANI, Roberto. Oscuri martiri, eroi del dovere: memoria e celebrazione del maestro elementare attraverso i necrologi pubblicati sulle riviste didattiche e magistral nel primo secolo dell'Italia unita (1861-1961). Milano: Franco Angeli, 2016

BASTOS, Maria Helena Camara. Culturas e história da educação: desafios para a pesquisa. ENCONTRO SUL-RIOGRANDENSE DE PESQUISADORES EM HISTÓRIA DA EDUCAÇÃO, 21, 2015. Anais ... Caxias do Sul: UCS/Asphe, 2015.

PRIKLADNICKI, Fábio. A arte do obituário. Zero Hora. Segundo Caderno. Porto Alegre, 15 jul. 2015, p. 3. 
MARIA HELENA CAMARA BASTOS é professora na Pontifícia Universidade Católica do Rio Grande do Sul. Professora visitante na Università degli studi di Macerata/Itália.

Endereço: Rua Eng. Álvaro Nunes Pereira, 340/906 - 90570-110 - Porto Alegre - RS - Brasil.

E-mail: mhbastos1950@gmail.com.

Recebido em 12 de fevereiro de 2016.

Aceito em 14 de abril de 2016. 